\title{
New insights into the effects of biomaterial chemistry and topography on the morphology of kidney epithelial cells
}

Citation for published version (APA):

Hulshof, F., Schophuizen, C., Mihajlovic, M., van Blitterswijk, C., Masereeuw, R., de Boer, J., \& Stamatialis, D. (2018). New insights into the effects of biomaterial chemistry and topography on the morphology of kidney epithelial cells. Journal of Tissue Engineering and Regenerative Medicine, 12(2), E817-E827. https://doi.org/10.1002/term.2387

Document status and date:

Published: 01/02/2018

DOI:

10.1002/term.2387

Document Version:

Publisher's PDF, also known as Version of record

Document license:

Taverne

Please check the document version of this publication:

- A submitted manuscript is the version of the article upon submission and before peer-review. There can be important differences between the submitted version and the official published version of record.

People interested in the research are advised to contact the author for the final version of the publication, or visit the DOI to the publisher's website.

- The final author version and the galley proof are versions of the publication after peer review.

- The final published version features the final layout of the paper including the volume, issue and page numbers.

Link to publication

\footnotetext{
General rights rights.

- You may freely distribute the URL identifying the publication in the public portal. please follow below link for the End User Agreement:

www.umlib.nl/taverne-license

Take down policy

If you believe that this document breaches copyright please contact us at:

repository@maastrichtuniversity.nl

providing details and we will investigate your claim.
}

Copyright and moral rights for the publications made accessible in the public portal are retained by the authors and/or other copyright owners and it is a condition of accessing publications that users recognise and abide by the legal requirements associated with these

- Users may download and print one copy of any publication from the public portal for the purpose of private study or research.

- You may not further distribute the material or use it for any profit-making activity or commercial gain

If the publication is distributed under the terms of Article $25 f a$ of the Dutch Copyright Act, indicated by the "Taverne" license above, 


\title{
New insights into the effects of biomaterial chemistry and topography on the morphology of kidney epithelial cells
}

\author{
Frits Hulshof ${ }^{1,2}$, Carolien Schophuizen ${ }^{3,4,5}$, Milos Mihajlovic ${ }^{5,6}$, Clemens van Blitterswijk ${ }^{6}$, \\ Rosalinde Masereeuw ${ }^{5,7}$, Jan de Boer ${ }^{2}$ and Dimitrios Stamatialis ${ }^{1 *}$ \\ ${ }^{1}$ Department of Biomaterials Science and Technology, MIRA Institute for Biomedical Technology and Technical Medicine, University of \\ Twente, Enschede, The Netherlands \\ ${ }^{2}$ Department of Cell Biology inspired Tissue Engineering, MERLN Institute for Technology-Inspired Regenerative Medicine, University of \\ Maastricht, Maastricht, The Netherlands \\ ${ }^{3}$ Department of Pediatric Nephrology, Radboudumc, Nijmegen, The Netherlands \\ ${ }^{4}$ Department of Physiology, Radboudumc, Radboud Institute for Molecular Life Sciences, Nijmegen, The Netherlands \\ ${ }^{5}$ Department of Pharmacology and Toxicology, Radboudumc, Radboud Institute for Molecular Life Sciences, Nijmegen, The Netherlands \\ ${ }^{6}$ Department of Complex Tissue Regeneration, MERLN Institute for Technology-Inspired Regenerative Medicine, University of Maastricht, \\ Maastricht, The Netherlands \\ ${ }^{7}$ Division of Pharmacology, Utrecht Institute for Pharmaceutical Sciences, Utrecht, The Netherlands
}

\begin{abstract}
Increasing incidence of renal pathology in the western world calls for innovative research for the development of cell-based therapies such as a bioartificial kidney (BAK) device. To fulfil the multitude of kidney functions, the core component of the BAK is a living membrane consisting of a tight kidney cell monolayer with preserved functional organic ion transporters cultured on a polymeric membrane surface. This membrane, on one side, is in contact with blood and therefore should have excellent blood compatibility, whereas the other side should facilitate functional monolayer formation. This work investigated the effect of membrane chemistry and surface topography on kidney epithelial cells to improve the formation of a functional monolayer. To achieve this, microtopographies were fabricated with high resolution and reproducibility on polystyrene films and on polyethersulfone-polyvinyl pyrrolidone (PES-PVP) porous membranes. A conditionally immortalized proximal tubule epithelial cell line (ciPTEC) was cultured on both, and subsequently, the cell morphology and monolayer formation were assessed. Our results showed that L-dopamine coating of the PES-PVP was sufficient to support ciPTEC monolayer formation. The polystyrene topographies with large features were able to align the cells in various patterns without significantly disruption of monolayer formation; however, the PES-PVP topographies with large features disrupted the monolayer. In contrast, the PES-PVP membranes with small features and with large spacing supported well the ciPTEC monolayer formation. In addition, the topographical PES-PVP membranes were compatible as a substrate membrane to measure organic cation transporter activity in Transwell@ systems. Copyright (C) 2016 John Wiley \& Sons, Ltd.
\end{abstract}

Received 28 April 2016; Revised 17 November 2016; Accepted 6 December 2016

Keywords bioartificial kidney; kidney epithelial cells; surface topography; biomaterial chemistry; cell morphology and function; membrane

\section{Introduction}

Surface microtopography has a strong influence on the response of various cell-types to biomaterials (HoffmanKim et al., 2010; Justesen et al., 2009; Lovmand et al., 2009; Unadkat et al., 2011). In fact, applying optimized surface topography to biomedical devices such as implants can improve tissue integration and host response. Optimal biomaterial-cell interaction is also extremely important for the development of bioartificial organs where artificial membranes are combined with cells and tissues, such as

*Correspondence to: Dimitrios Stamatialis, Department of Biomaterials Science and Technology, MIRA Institute for Biomedical Technology and Technical Medicine, University of Twente, Enschede, The Netherlands. E-mail: d stamatialis@utwente.nl in the bioartificial kidney (BAK). A key requirement for a BAK is the formation of a living membrane consisting of a tight kidney cell monolayer with preserved functional organic ion transporters, on suitable artificial membrane surfaces (Saito et al., 2011). Haemodialysis, which mimics the glomerulus, mainly removes small, unbound substances, while leaving large and protein-bound uremic solutes attached. The application of a BAK, which mimics the proximal tubule, in combination with haemodialysis could perform complete blood filtration and replace the endocrine, metabolic and immune-modulatory functions of the kidney (Buffington et al., 2014; Humes et al., 2014). Therefore, it may reduce the incidence of secondary morbidities in patients, and shorten dialysis duration or frequency, thereby improving the quality of life of patients with end stage renal disease (Ni et al., 2011; 
Schophuizen et al., 2015). In a BAK, one side of the artificial polymeric membrane is in contact with blood and therefore should be highly haemocompatible to prevent blood activation and coagulation, whereas the other side should be cytocompatible and bioactive for adhesion of the renal epithelial cells. This living membrane should allow for transport of nutrients and solutes, including metabolic waste products to the cells for excretion, but also should block immune proteins from reaching the cells.

Throughout the years, most studies on the development of a living membrane with renal epithelial cells have focused on improving cell adhesion on polyethersulfone (PES) and polysulfone based membranes by application of coatings of extracellular matrix components (FeyLamprecht et al., 1998, 2000; Sato et al., 2005). However, in many cases maintenance of a transmonolayer transport activity and monolayer integrity was not possible (Fujita et al., 2002; Ip et al., 1988; Kanai et al., 1999; van der Aa et al., 2010; Zhang et al., 2009). Recently, proof of concept was shown of a living membrane by applying a double coating of 3,4-dihydroxy-L-phenylalanine (L-DOPA) and human collagen IV (Coll IV) on PES membranes combined with conditionally immortalized proximal tubule epithelial cells (ciPTEC) (Schophuizen et al., 2015). Very few studies have focused on the effect of membrane micro- and nanotopography on the kidney cell monolayer formation. For example, human embryonic kidney cell line (HEK-293) showed enhanced adhesion, proliferation on and alignment to microstructured substrates (Rebollar et al., 2008). Submicron topography in combination with flow-induced shear stress (FSS) enhanced tight junction formation and cell-alignment (Frohlich et al., 2012), leading to a more in vivo-like phenotype and faster tight junction formation (Frohlich et al., 2013). This suggests a correlation between kidney cell morphology and kidney cell function.

This work investigates the effect of surface topography on renal epithelial cells. The ciPTECs were chosen as a cell model to investigate functional monolayer formation, because they possess several renal epithelial phenotypic features, including key transport proteins (Jansen et al., 2014; Wilmer et al., 2010). Previous high-throughput experiments performed in the author laboratory using the TopoChip screening platform (Hulsman et al., 2015; Unadkat et al., 2011) identified a set of seven microtopographies that are able to induce biological effects for various cells. For example, several of these topographies were able to induce strong cell orientation, even though the patterns were very different than those previously used for alignment of various cell types (Charest et al., 2007; Lücker et al., 2014; Luna et al., 2011). Here, these topographies are produced on polystyrene (PS) films via hot embossing to investigate ciPTEC response to topographies and on PES based porous membranes. The latter are selected due to their nonfouling properties and history as a material used in blood filtration systems, and compatibility with ciPTEC (Schophuizen et al., 2015). The PES porous microstructured membranes were prepared by phase separation micromoulding (PS $\mu \mathrm{M})$, a method for combining surface topography and porosity in one step (Papenburg et al., 2007; Vogelaar et al., 2005). To the best of the authors' knowledge, this is the first study to present the development of a set of microstructured PS and porous PES substrates and to investigate in detail the effects of surface topography on the adhesion, proliferation and morphology of kidney epithelial cells.

\section{Materials and methods}

\subsection{Fabrication of PS microstructured films}

The topographies were produced on PS by hot embossing of a PS film (Goodfellow Huntingdon, UK). The inverse structure of the topographies was produced on silicon by standard photolithography and deep reactive etching. The silicon mould was used to make a positive mould on poly(dimethylsiloxane) (PDMS). The PDMS mould was required to create a second negative mould in OrmoStamp ${ }^{\circledR}$ hybrid polymer (micro resist technology Gmbh), which served as the mould for hot embossing the PS films. The fabrication of the OrmoStamp mould was necessary due to the fact that demoulding of PS from silicon often leads to destruction of the mould or the imprint. The hot embossing conditions were $120^{\circ} \mathrm{C}$ for $5 \mathrm{~min}$ at pressure of $10 \mathrm{Bar}$, with a demoulding temperature of $80^{\circ} \mathrm{C}$.

\subsection{Fabrication of PES-based microstructured porous membranes}

Porous microstructured membranes were produced by PS $\mu \mathrm{M}$ (Papenburg et al., 2007; Vogelaar et al., 2005). There, the appropriate solution is cast onto a microstructured master mold. Solvent and nonsolvent liquid exchange initiates phase separation until the polymer solution contains sufficient nonsolvent to precipitate. By selecting the right solvent/nonsolvent system with the specific polymer, the porosity of the resulting membrane can be tuned. The silicon moulds were fabricated by standard photolithography techniques. To increase mould hydrophilicity, a $100-\mathrm{nm}$ silicon oxide layer was created on the mould by wet oxidation. The method was optimized using TopoChip moulds fabricated by photolithography and directed reactive etching Unadkat et al., 2011. The mould contains a pattern that creates a grid of walls with a height of $40 \mu \mathrm{m}$ and a width of $10 \mu \mathrm{m}$. Between the walls are topographical structures with discrete shapes and a height of $10 \mu \mathrm{m}$. The walls are good structures to test fabrication of features with higher aspect ratios, which can be more challenging.

A PES (Fluka)-polyvinylpyrrolidinone K90 (PVP; Fluka) solution was prepared in 1-methyl-2 pyrrolidinone (NMP; Acros Organics). The solution was degassed and cast on the moulds. Two polymer dope compositions were 
tested: 10\% PES + 6.6\% PVP + 83.3\% NMP $(w / w)$ and $15 \%$ PES $+10 \%+75 \%$ NMP $(w / w)$. Two non-solvent compositions were tested: ultrapure water (MilliQ $18 \mathrm{M} \Omega \mathrm{cm}$; Millipore, Billerica, MA, USA) and 50\% water $+50 \%$ NMP $(v / v)$. Two different phase separation temperatures were tested: room temperature and $1^{\circ} \mathrm{C}$. After casting, the mould with solution was quickly placed in the non-solvent bath. The solvent exchange was allowed to take place until complete demixing, which could last for up to several hours. Then, the porous microstructured membranes were washed in water. The water was refreshed three times a week for at least 3 weeks to remove all traces of NMP. In most cases the membranes were stored in $70 \%$ ethanol after washing. If the membranes were used immediately after washing, the membranes were sterilized with $70 \%$ ethanol for $1 \mathrm{~h}$ prior to cell culture.

\subsection{Cell culture and microscopy}

The ciPTECs, clone 21.2 were isolated from kidney tissue and cultured as described elsewhere (Jansen et al., 2014). The cells were cultured in Dulbecco's modified Eagle's medium/HAMS's F12 medium (Gibco) containing 10\% FCS (Lonza) $5 \mu \mathrm{g} / \mathrm{ml}$ insulin, $5 \mu \mathrm{g} / \mathrm{ml}$ transferrin, $5 \mathrm{ng} / \mathrm{ml}$ selenium, $36 \mathrm{ng} / \mathrm{ml}$ hydrocortisone, $10 \mathrm{ng} / \mathrm{ml}$ EGF and $40 \mathrm{pg} / \mathrm{ml}$ tri-iodothyronine.

For the cell culture, the PES membranes were coated with either L-DOPA alone for 30 min or with combination of L-DOPA and Coll IV following the procedure described elsewhere (Schophuizen et al., 2015). Briefly, L-DOPA (Sigma-Aldrich, Zwijndrecht, the Netherlands) was dissolved at $2 \mathrm{mg} / \mathrm{ml}$ in Tris buffer $10 \mathrm{mM}$ ( $\mathrm{pH} \mathrm{8.5)} \mathrm{for}$ $1 \mathrm{~h}$ at $37^{\circ} \mathrm{C}$. Before culture, the coated membranes were washed with Hanks' balanced salt solution (HBSS; Gibco). The Coll IV coating solution of $50 \mu \mathrm{g} / \mathrm{ml}$ was prepared by dissolving Coll IV (Sigma-Aldrich) for $2 \mathrm{~h}$ at $37^{\circ} \mathrm{C}, 5 \% v / \mathrm{v} \mathrm{CO}_{2}$.

The ciPTECs were seeded at a density of 60,000 cells $/ \mathrm{cm}^{2}$ on the membranes and before immuno-staining the cells were washed with HBSS and fixated for $5 \mathrm{~min}$ with $2 \%$ paraformaldehyde, $4 \%$ sucrose in HBSS. The cells were permeabilized with $0.3 \%$ Triton X 100 (Sigma-Aldrich) in PBS for $10 \mathrm{~min}$, before blocking with $2 \%$ fetal bovine serum, $2 \%$ bovine serum albumin, $0.1 \%$ Tween in PBS. After blocking, the cells were incubated over-night at $4^{\circ} \mathrm{C}$ with primary antibodies ( $\alpha \mathrm{ZO}-1$; Santa Cruz Biotechnology) in blocking solution. The membranes were washed four times for 10 min each before secondary antibody (Goat anti rabbit-Alexa488; Invitrogen) incubation of $1 \mathrm{~h}$ at room temperature. In the initial experiment with the PS substrates, phalloidin-Alexa594 was also added during the secondary antibody incubation to act as a counterstain to ease alignment assessment. After four more washing steps and 10-minute incubation in 4',6-diamidino-2-phenylindole (DAPI; Sigma-Aldrich) the membranes with cells were mounted with Mowiol for microscopy on a coverslip. The cell imaging was performed using BD Pathway 435 automated fluorescence microscope. Image quantifications were performed by a custom made Cellprofiler pipeline (available on request) (Carpenter et al., 2006). The cell alignment was estimated by binning the data in $10^{\circ}$ wide groups and summing the three highest bin percentages to show the relative amount of cells aligned within the major $30^{\circ}$ angle.

\subsection{Scanning electron microscopy}

Images were taken by Philips XL-30 scanning electron microscope (SEM). Prior to scanning the samples were sputtered with gold for $40 \mathrm{~s}$. From the SEM images, the pore size was measured with ImageJ (Schneider et al., 2012).

\subsection{Transport measurements}

The transepithelial transport of $\left[{ }^{14} \mathrm{C}\right]$-creatinine and $\left[{ }^{3} \mathrm{H}\right]$ inlulin by matured ciPTEC monolayers cultured on either polyester or PES-PVP membranes was measured using a Transwell@ culture system. During the preparation of this experiment, membranes (stored in ethanol) were punched using a 12-mm skin biopsy puncher, and subsequently they were attached to the Transwell culture system with custom-made sealing rings. Then the L-DOPA coating was performed as described. All PES microstructured membranes and the reference Polyester Transwells (diameter $12 \mathrm{~mm}$, pore size $0.4 \mu \mathrm{m}$ ) were coated with only L-DOPA solution, as described earlier. Mature cell monolayers were washed very carefully in modified Krebs-Henseleit buffer (Sigma-Aldrich) including $10 \mathrm{~mm}$ Hepes ( $\mathrm{pH}$ 7.4). Subsequently, all membranes were preincubated in Krebs-Henseleit-Hepes buffer ( $0.5 \mathrm{~mL}$ apically, $1.5 \mathrm{~mL}$ basolaterally) for $2 \mathrm{~h}$ at $37^{\circ} \mathrm{C}, 5 \%(\mathrm{v} / \mathrm{v}) \mathrm{CO}_{2}$. Transport was initiated by the basolateral addition of either $\left[{ }^{14} \mathrm{C}\right]$-creatinine $(0.75 \mu \mathrm{M}$, $2 \mu \mathrm{Ci} / \mathrm{ml})$ or $\left[{ }^{3} \mathrm{H}\right]$-inulin $(0.45 \mu \mathrm{M}, 20 \mu \mathrm{Ci} / \mathrm{ml})$ with or without cimetidine $(100 \mu \mathrm{M})$ and metformin $(100 \mu \mathrm{M}$; Sigma-Aldrich) as competitors for organic cation transport (Schophuizen et al., 2013). At the start of the measurement, a $20 \mu \mathrm{L}$ reference sample was taken from the basolateral exposure compartment. After $30 \mathrm{~min}$ of incubation with gentle agitation at $37^{\circ} \mathrm{C}$, a $200 \mu \mathrm{L}$ sample was removed from the apical chamber. The activity of $\left[{ }^{3} \mathrm{H}\right]$ and $\left[{ }^{14} \mathrm{C}\right]$ in the samples was determined by liquid scintillation counting (Beckman). The fluxes of $\left[{ }^{14} \mathrm{C}\right]$ creatinine or $\left[{ }^{3} \mathrm{H}\right]$-inulin through the membranes were determined for each separate Transwell. The flux of $\left[{ }^{3} \mathrm{H}\right]$-inulin was used as an internal leakage marker.

\section{Results}

\subsection{Fabrication of microstructured PS nonporous films}

Figure 1 presents typical images of the topographies produced on PS by photolithography and hot embossing. 
t1

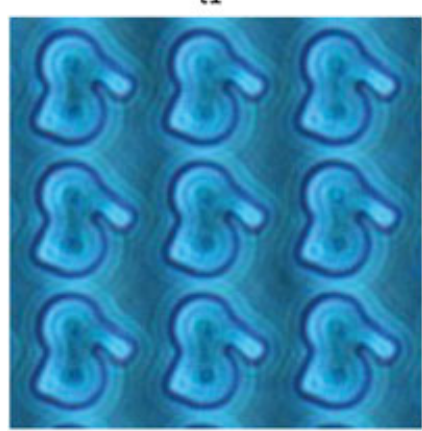

t5

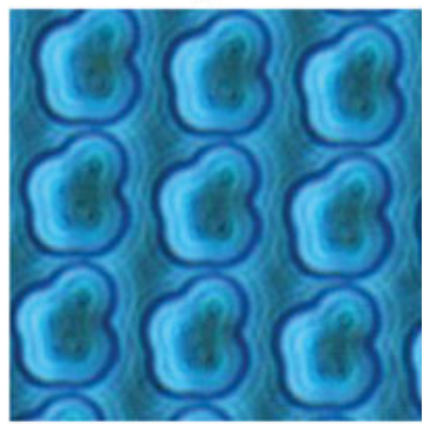

t8

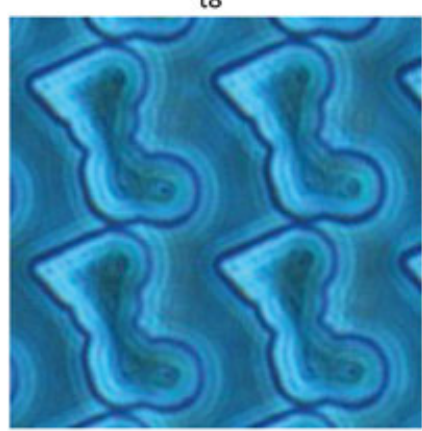

t2

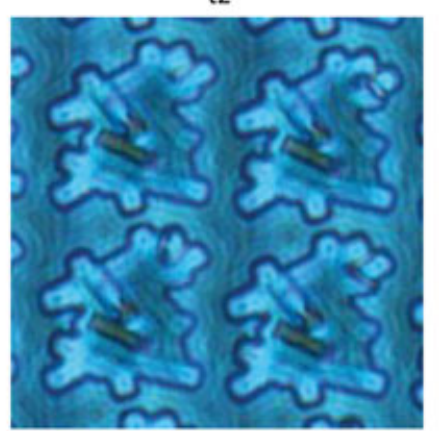

t6

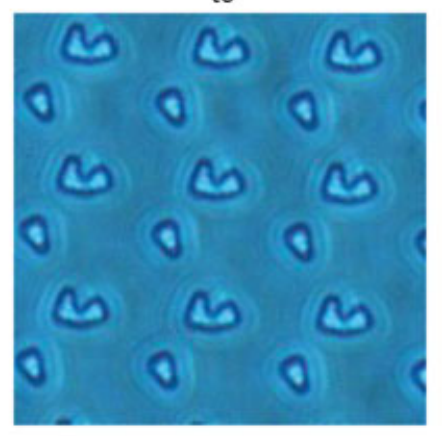

$50 \mu \mathrm{m}$ t3

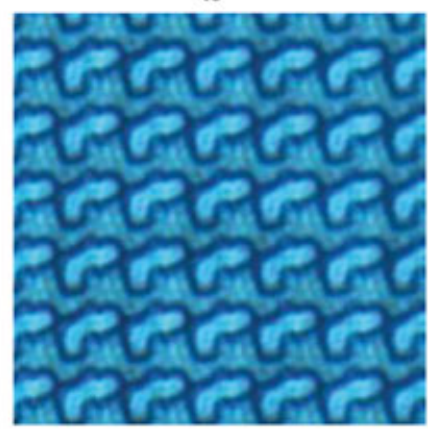

t7

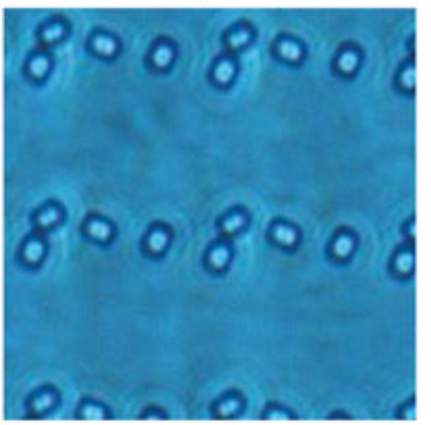

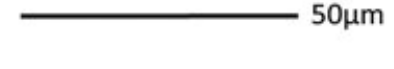

Figure 1. Optical microscopy images of PS topographies produced by hot embossing. High-throughput experiments performed in the authors' laboratory using the TopoChip screening platform identified this set of seven topographies, which are able to induce various biological effects such as cell orientation and cell morphology

This set provides a rather broad range of topographic features with round and sharp edges and size and spacing varying between 5 and $30 \mu \mathrm{m}$. The features on the topographies $\mathrm{t} 1$ and $\mathrm{t} 5$ are medium sized $(10-20 \mu \mathrm{m})$ with spacing of $5-10 \mu \mathrm{m}$ whereas those on the $\mathrm{t} 2$ and $\mathrm{t} 8$ topographies are relatively large $(20-30 \mu \mathrm{m})$ with spacing of 5-10 $\mu \mathrm{m}$. The features on the topographies t6 and t7 are relatively small $(<5 \mu \mathrm{m})$ with large spacing of $>20 \mu \mathrm{m}$, whereas on the topography $\mathrm{t} 3$, the features are small with almost no space between them.

\subsection{Fabrication of PES based porous microstructured membranes}

Initial tests showed that the silicon moulds were very hydrophobic and the PES/PVP solutions could not be cast well resulting in membranes with poor feature replication (Figure 2a). In this case, the polymer solution could not penetrate into the features to form the microtopographies. To improve the interaction between the mould and the polymer solution, the moulds were coated with a $100-\mathrm{nm}$ silicon oxide layer, created by wet oxidation. This allowed casting of the solutions successfully to the moulds.

The casting of $10 \%$ PES / 6.6\% PVP $(w / w)$ in NMP solution with water as a non-solvent did not produce membranes with good quality features. The solution could penetrate the ridges, but the resulting walls were damaged during demoulding (Figure 2b). The feature replication was also rather poor. Casting of a higher polymer dope concentration of 15\% PES + 10\% PVP in NMP $(w / w)$ improved the quality of the replication of the topographies, but it was not yet satisfactory. In this case, large voids were visible in the membranes and walls (Figure 2c) probably due to the rapid demixing of solvent and non-solvent. To avoid this, the demixing process was slowed down, using a mixture of $50 \%$ water $+50 \%$ NMP $(v / v)$ as a non-solvent. The new membranes have mostly intact walls with small defects and the topographical structures have better defined edges comparable to those produced by hot embossing (Figure 2d). However, a significant amount of the features were deformed. The 
(a)

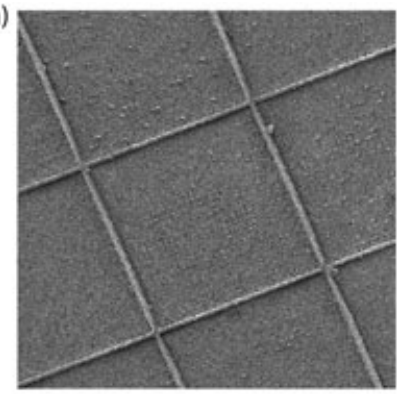

(d)

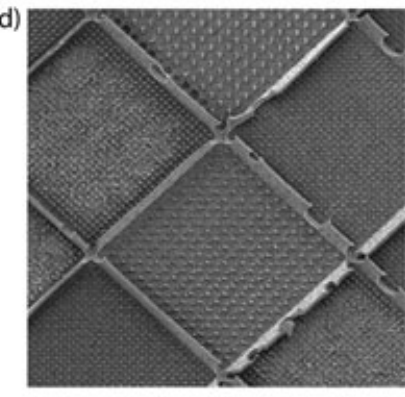
$300 \mu \mathrm{m}$

(g)

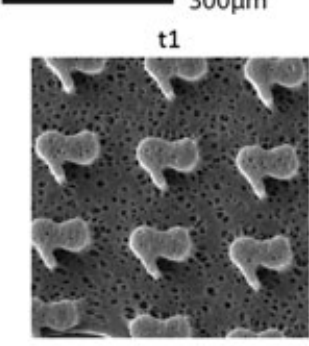

t6

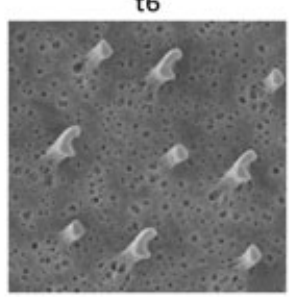

(b)

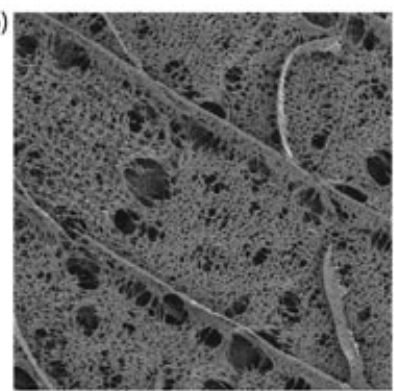

(e)
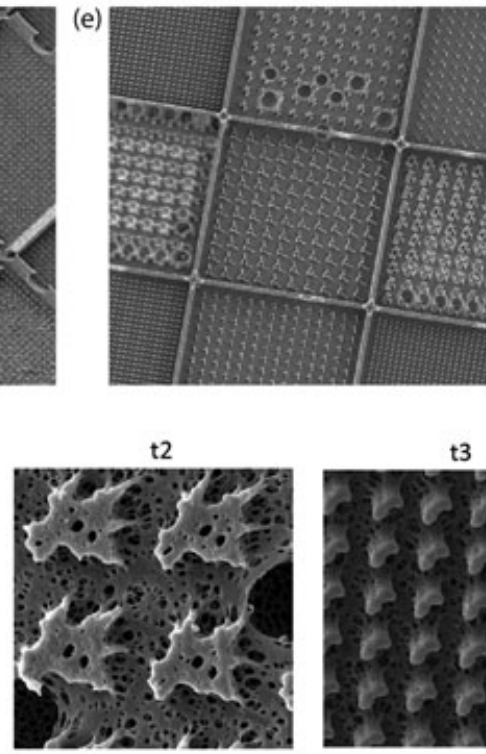

t7

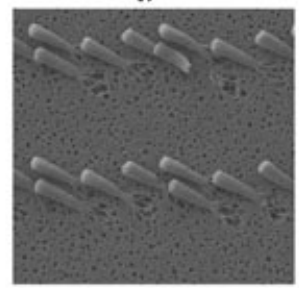

Mean poresize

(h)
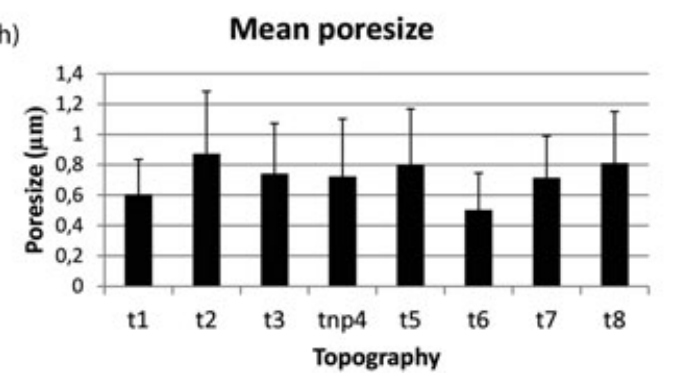
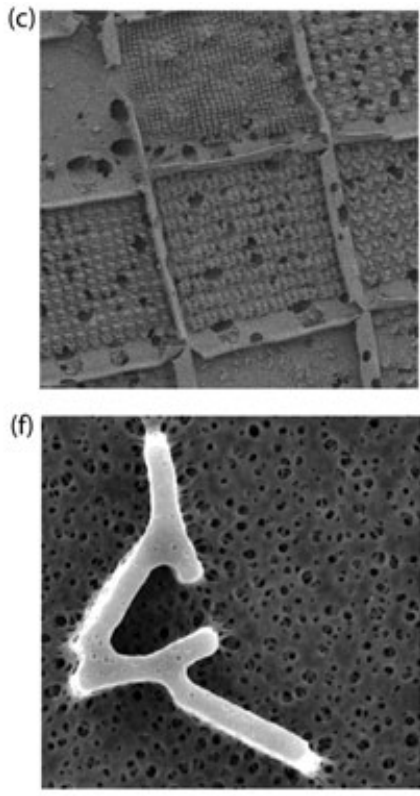

- $10 \mu \mathrm{m}$

t5

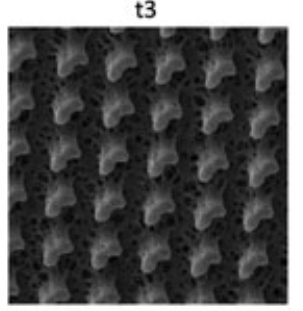

t8

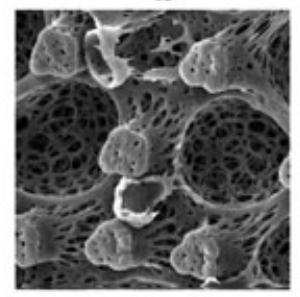

$-10 \mu \mathrm{m}$
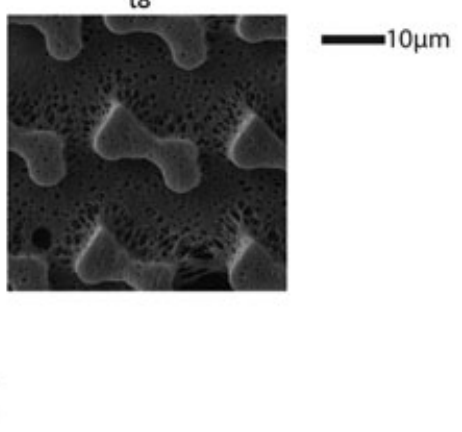
diameter of $0.8 \mu \mathrm{m}$ with rather large standard deviation of $0.3 \mu \mathrm{m}$ and there is no significant difference in pore size between the various microstructured membranes (Figure 2h). This pore size is expected to allow free transport of water and uraemic toxins through the membrane while it should prevent the infiltration of the kidney epithelial cells, which have size of $>20 \mu \mathrm{m}$ (Jansen et al., 2014). Note that for the BAK, the cell layer on top of the PES porous membranes should form a true barrier that will restrict the loss of albumin and IgG, but also contains transport proteins that work in concert in the excretion of waste products, many of which are bound to plasma proteins. In order to be excreted in the extracorporeal compartment, these protein-bound uraemic toxins should be delivered in close proximity to the cells for which the unrestricted permeability through the PES membranes is a prerequisite.

The dimensions of topographies on PES membranes are quite similar to those on PS with a slightly lower resolution due to the porosity and shrinkage of $13.3 \%$ caused during the PS $\mu \mathrm{M}$. For some of the larger topographies, for example $\mathrm{t} 2$ and $\mathrm{t} 5$, there are occasionally crater shaped structures with a diameter between 10 and $20 \mu \mathrm{m}$ and a depth of $5-10 \mu \mathrm{m}$ close to the topographies (Figure $2 \mathrm{~g}$ ). These artefacts are frequent and should not have a significant effect on the topography response. Besides, they have the similar porosity to the rest of the membrane surface and therefore are not expected to affect the membrane transport properties.

\subsection{Cell culture on PS films}

Surface topography affects morphology and function of many cell types (Flemming et al., 1999). In the case of kidney epithelial cells, other studies have indicated that topography can induce alignment resulting in a more in vivo-like phenotype and faster tight junction formation (Frohlich et al., 2012). Here, the CiPTECs were cultured for 1 week on the microstuctured and a non-patterned PS films, the latter used as a reference. The morphology of the cells was visualized by staining filamentous actin with phalloidin, tight junctions with Zona Occludens 1 (ZO1) and the DNA with DAPI. ZO1 is a critical component of tight-junctions, which enable cells to form an impermeable barrier to solutes (Denker and Sabath, 2011; Van Itallie et al., 2009). Because of this, it acts as a marker for cell polarity and integrity of the cell monolayer.

The CiPTEC form confluent cell layers on all PS films (Figure 3a). These films support the adhesion and proliferation of ciPTECs well, without the need of applying any coatings. Besides, the surface topography strongly influences cell morphology. For the topographies with relatively large features ( $t 1, t 2, t 5$ and $t 8)$ the cells attach between the microstructures, become rather thin and elongated and form a grid-like pattern, which aligns them. For the topographies with smaller features ( $\mathrm{t} 3, \mathrm{t} 6$ and $\mathrm{t} 7$ ) the cells align without creating grid-like patterns and do not alter the cell morphology much compared to the non-patterned surface, tnp4. The cells are guided by the smaller topographies but are not confined by them.

The cell alignment in the confluent monolayers was quantified by measuring the percentage of nuclei in the total set of images that were aligned within $10^{\circ}$ of the major axis with Cell Profiler software (Carpenter et al., 2006) (Figure 3b). Two of the topographies ( $t 3$ and $t 5$ ) showed high degrees of alignment. Representative images of nuclei and corresponding alignment distributions are shown in Figure $4 c$ and $4 d$, respectively. Clearly visible are the high alignment of $\mathrm{t} 3$, low alignment of $\mathrm{t} 6$ and alignment on the non-patterned surface tnp4. The t3 has the highest alignment of $54 \%$ of cells within $10^{\circ}$ of the main axis. This is higher than the previously reported alignment of ciPTEC on grated topographies, which was 35\% (Frohlich et al., 2013). This demonstrates that properly designed microstructures can achieve alignments that are the same or better than grated nanotopographies. It is important to note that the cells on the non-patterned substrate (tnp4) also show considerable alignment due to the fact that cells in confluent layers tend to align in bundles on a two-dimensional surface. However, this alignment is not in one direction. In fact, the overall alignment of cells over a larger surface of $>1 \mathrm{~cm}^{2}$, is around $31 \%$ within $10^{\circ}$ of the major axis. Finally, other topographies such as t6 induce much lower cell organization and alignment, suggesting that perhaps the features there disturb the formation of confluent cell monolayer.

\subsection{Cell culture on PES membranes}

To assess response of ciPTECs to the PES microstructured membranes, the cells were cultured there for 1 week. Due to the non-fouling properties of PES, the cell adhesion was extremely poor as only several cells were visible on an area as large as $1 \mathrm{~cm}^{2}$ (Figure 4a). To address this issue, the membranes were coated with either L-DOPA or with a double coating of L-DOPA and Coll IV. Earlier work showed that a double coating of L-DOPA and Coll IV provided the best substrate for ciPTEC monolayer formation (Schophuizen et al., 2015). The L-DOPA coating is expected to create a negatively charged surface, to increase membrane hydrophilicity (Schophuizen et al., 2015; Zhang et al., 2009; Zhu et al., 2009) and to increase adhesion of extracellular matrix (ECM) proteins to the surface, thereby increasing cell adhesion. The coatings were applied to one side of the membrane only, leaving the other side of the membrane resistant to fouling. In this work, the coating procedure was optimized to achieve coating layers in the nanometer range and avoid changing the quality of the microstructured features (Figure 4b). When the effect of the coatings on ciPTECs was assessed, it was observed that both the morphology and quality of cell monolayers on PES membranes coated only with L-DOPA or double coating L-DOPA/Coll IV were identical (Figure 4c). This is probably due to the use of the ciPTEC clone 21.2, which was isolated from kidney tissue and 
(a)
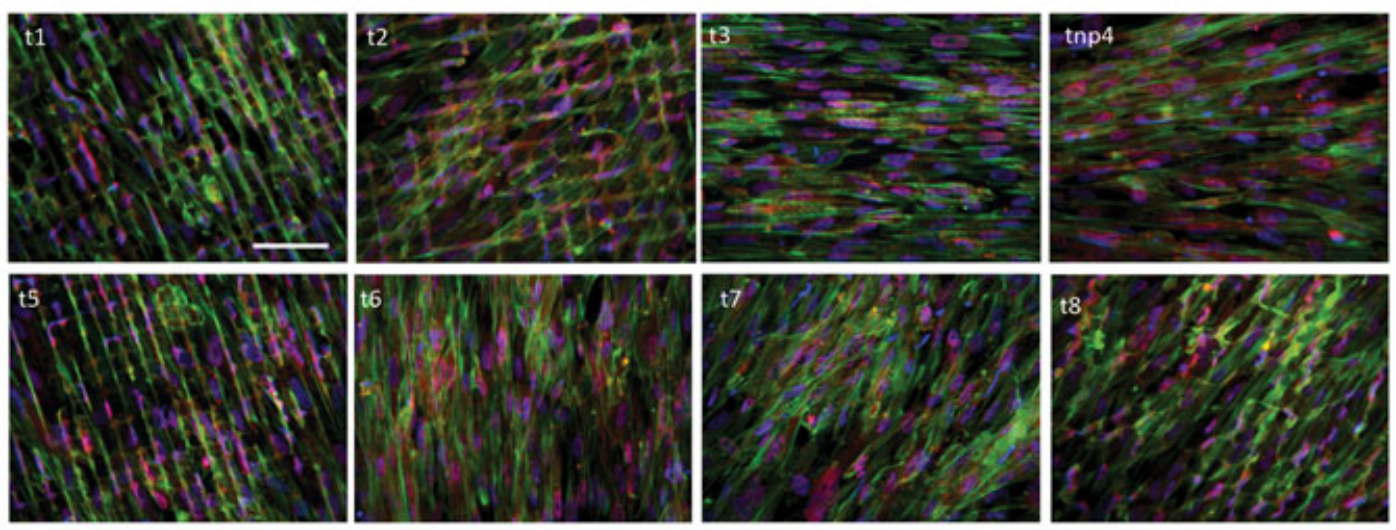

(b)

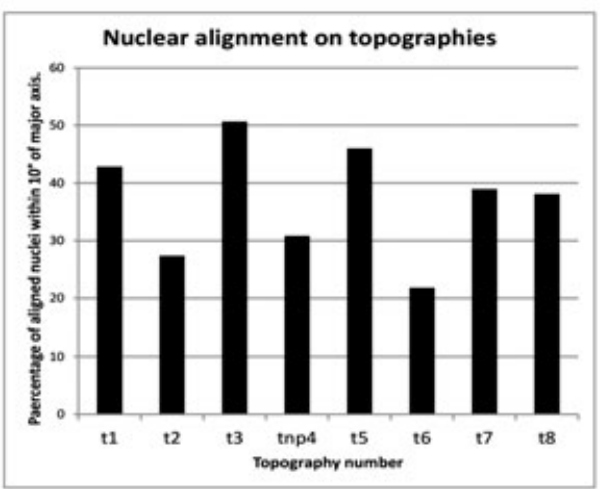

(c)
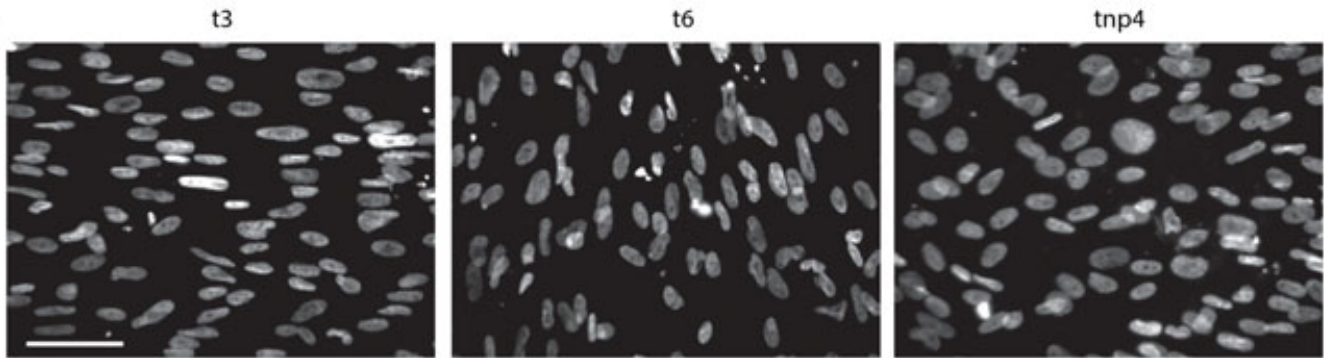

(d)
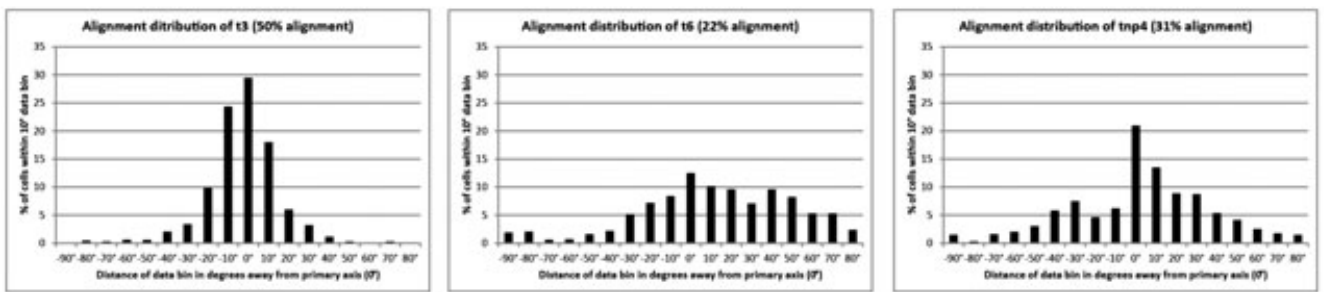

Figure 3. Morphology and alignment analysis of ciPTEC on PS topographies. (a) Fluorescence microscopy images of ciPTEC cultured on PS topographies, stained for DNA (blue), Filamentous actin (green), ZO-1 (red). Scale bars are $100 \mu \mathrm{m}$. (b) Quantitation of alignment of nuclei of ciPTEC within $10^{\circ}$ of the major axis on topographies. (c) Representative fluorescence images of nuclei which were used for quantitation (scale bars are $100 \mu \mathrm{m})$. (d) distributions of alignment corresponding to nuclei of (b)

can rapidly produce its own ECM (Jansen et al., 2014). In contrast to ciPTEcs isolated from urine (Wilmer et al., 2010) and other primary kidney cells (Zhang et al., 2009), which require coating with Coll IV, the 21.2 ciPTECs cells do not require this. Although more detailed investigation is required here, this finding suggests that 21.2 cells are excellent candidates for application in BAK without the need of expensive and time-consuming coatings of Coll IV.

When comparing ciPTEC morphology cultured on nonpatterned PS and L-Dopa coated PES membranes, the cell monolayers look very similar and homogenous. On both materials, the cells seem to form tight monolayers with clearly formed protein junctions between the cells, as concluded from the ZO1 staining. When comparing the effect of the topography on the cells for both materials, the microstructured PES membranes seem to have a more dramatic effect on the ciPTEC morphology and monolayer integrity in comparison to PS. The large features ( $\mathrm{t} 1, \mathrm{t} 2, \mathrm{t} 5$, t8) have a more disruptive effect on the cell monolayer, big holes can be seen on the cell monolayer (Figure 5d), whereas for the topographies $t 1, t 2$ and $t 8$, the cells form 
(a)

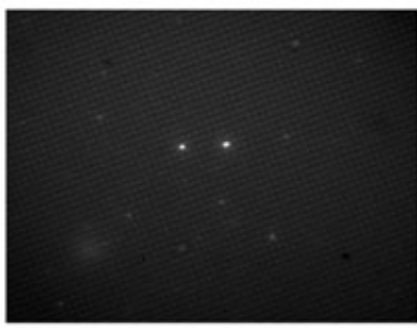

$600 \mu \mathrm{m}$

(c)

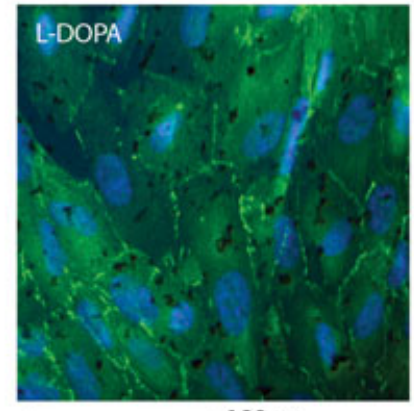

$100 \mu \mathrm{m}$

(d)
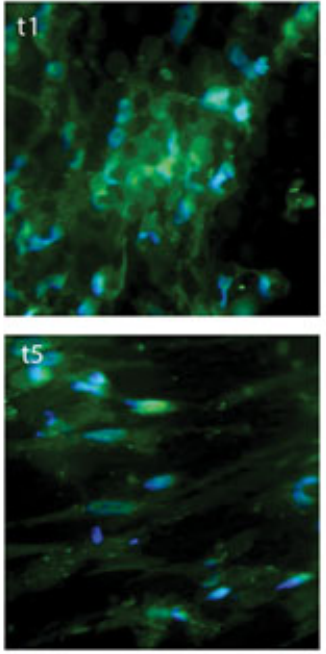

$100 \mu \mathrm{m}$

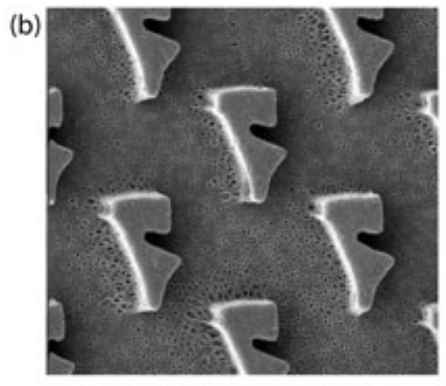

$10 \mu \mathrm{m}$
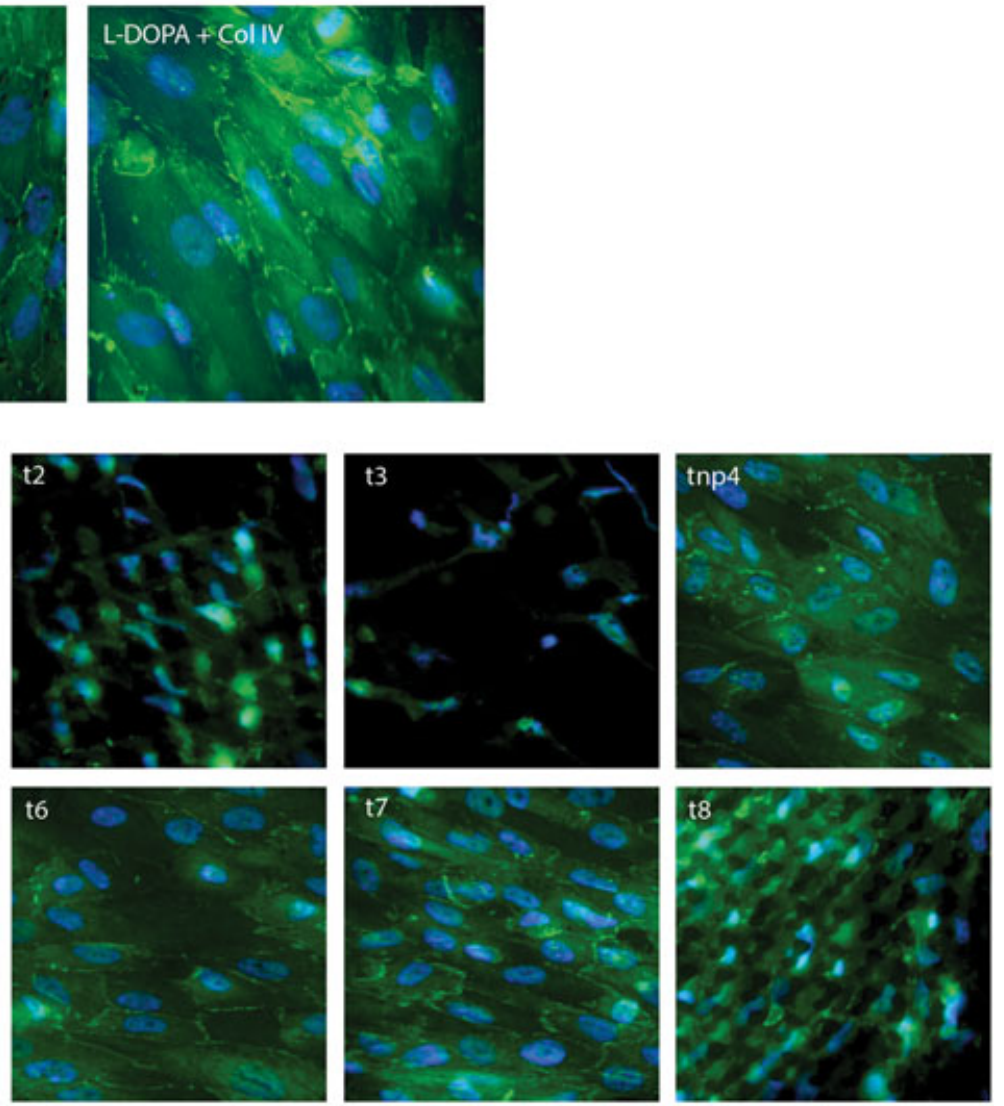

Figure 4. Kidney epithelial cells (ciPTEC) cultured on PES micro structured porous membranes. (a) Fluorescence microscopy image of ciPTEC cultured on uncoated PES-PVP membranes stained, with DAPI. (b) SEM image of a topographical feature on a porous PES membrane. (c) Fluorescence microscopy image of ciPTEC cultured on L-DOPA coated PES membranes and double coated membranes (L-DOPA + Collagen IV) PES membranes, stained for DNA (blue) and ZO-1 (green). (d) Representative images of ciPTEC cultured on L-DOPA coated porous PES microstructured membranes, stained for DNA (blue) and ZO-1 (green)

small islands with poorly defined tight-junctions. The topography $\mathrm{t} 3$, which has medium sized features with small spacing between them, has low number of cells. However, for the topographies with smaller features, such as t6 and t7, a good cell monolayer is created, and in the case of $t 7$, the features also seem to provide cues for cell alignment.

\subsection{Creatinine transport through the microstructured PES/PVP membranes}

Earlier studies showed that ciPTEC can achieve active transport of organic cations from the basolateral side to the apical side (Schophuizen et al., 2015, 2013). Here, the transport properties of the microstructured membranes with topographies $\mathrm{t} 3$, $\mathrm{t} 6$ and $\mathrm{t} 7$ are compared to the non-patterned membranes (tnp4) and polyester control membrane (Transwell). The membranes with topographies $\mathrm{t} 6$ and $\mathrm{t} 7$ were selected since they seem to support formation of a ciPTEC monolayer (see earlier section), whereas the membrane with topography $\mathrm{t} 3$ was chosen as a negative control since it disrupts the monolayer. To determine active transport by the cells, the creatinine flux was also measured in the presence of cimetidine, which competes with creatinine as a substrate for the organic cation transport proteins. To estimate monolayer leakage, inulin flux was also measured for every membrane because it crosses the epithelial membranes only by diffusion (Perrone, 1992). 
(a)
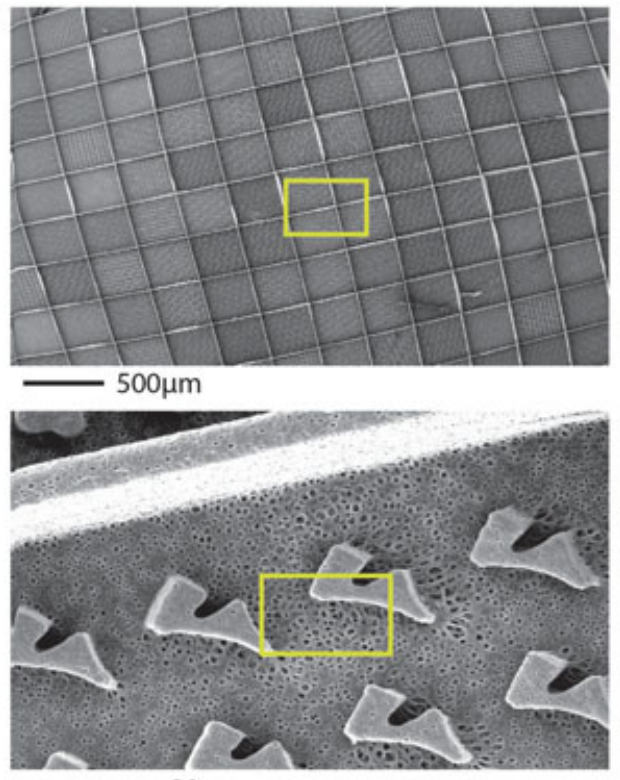

(b)
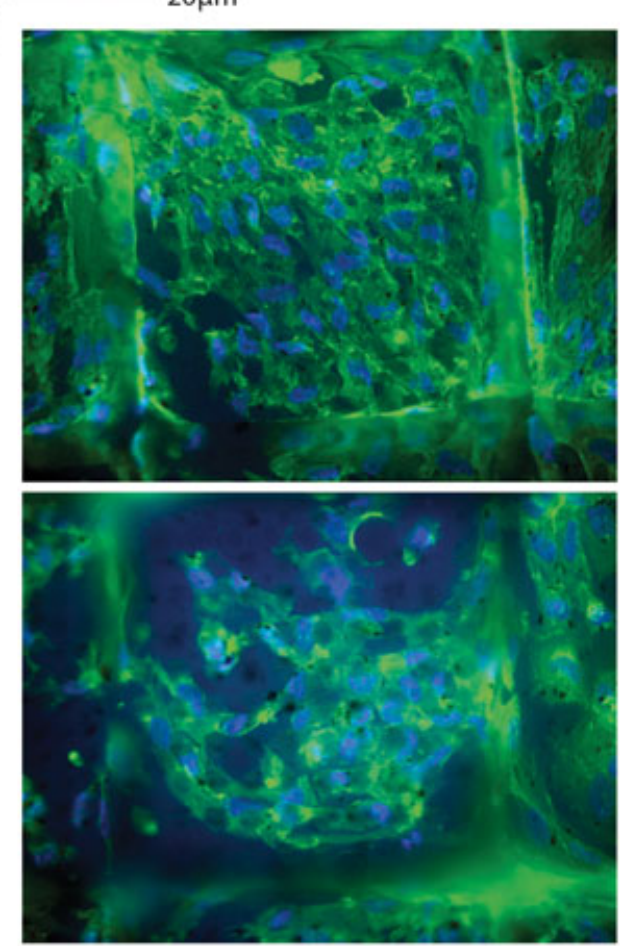

$100 \mu \mathrm{m}$
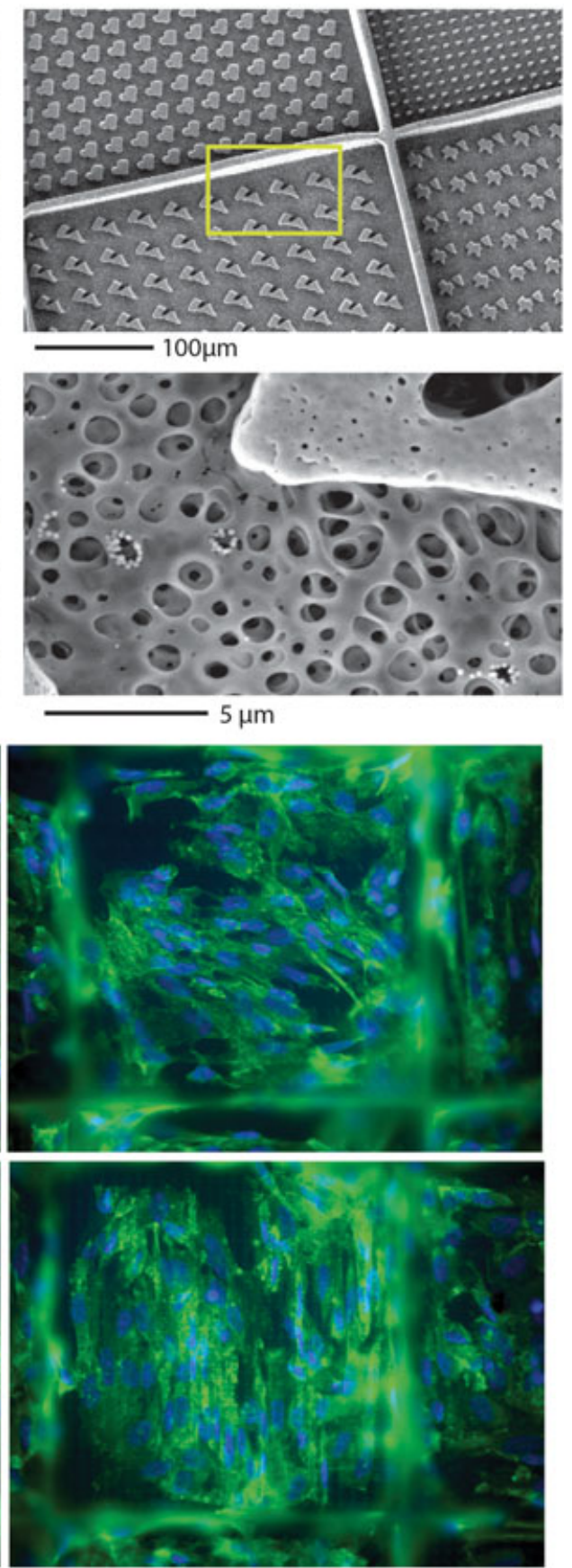

Figure 5. Porous PES TopoChips and culture of kidney epithelial cells (ciPTECs). (a) SEM images of a porous PES TopoChips. Yellow brackets indicate the location of the following zoomed in image. (b) Fluorescence microscopy image of ciPTEC cultured on porous PES TopoChips, stained for DNA (blue) and ZO-1 (green)

Supplementary Figure S1 shows the results of two experiments. The high variability between experiments greatly reduced the significance of the data, but clear trends can still be seen. The non-patterned (tnp4), the microstructured PES-PVP membranes with topography t7 and the commercial polyester membranes (PE np), all coated with L-DOPA alone, can actively transport creatinine, which decreases with addition of cimetidine (see all membranes + cim). Based on these preliminary data, there is no improved active creatinine transport observed in ciPTEC cultured on micropatterned membranes.

\section{Discussion}

This work investigated in detail the effects of the biomaterial surface topography on the adhesion, proliferation and morphology of kidney epithelial cells. 
For this, a set of microstructured PS (as a golden standard for cell culture studies) and PES based membranes [state of art material for (bio)artificial kidney devices] were developed and studied. A significant effort was put on the fabrication of excellent quality porous microstructured PES membranes. Important parameters to be tailored were the polymer concentration, temperature and the composition of the coagulation bath. In fact, a high polymer concentration, a decrease of the coagulation bath temperature from $20^{\circ} \mathrm{C}$ to $1^{\circ} \mathrm{C}$ and the use of non-solvent mixture of 50/50 $(v / \mathrm{v})$ water/ NMP resulted in the production of porous (mean pore size of $0.8 \mu \mathrm{m}$ ) microstructured membranes with features of excellent quality.

The ciPTECs were successfully cultured on both PS and the PES-PVP membranes. An important finding of this work is that a good quality cell monolayer can be achieved on porous PES membranes with the application of L-DOPA alone, without the need of extra coating with Coll IV, as found in earlier studies with ciPTECs isolated from human urine Schophuizen et al., 2015. This is probably because the ciPTEC clone used in this study, which was originally derived from kidney issue, shows higher expression of extracellular matrix genes Coll I and -IV $\alpha 1$ as compared to ciPTEC that originated from urine (Jansen et al., 2014).

Another important finding of this work is the striking difference between the response of ciPTECs on PS and PES membranes. While for PS the large topographic features did not adversely affect ciPTEC numbers and monolayer formation, the same features fabricated on PES disrupted the cell monolayer. For the PES membranes, the topographies with small features did not disrupt the monolayer and were able to induce cell organization and alignment. Alignment of kidney epithelial cells makes them more susceptible to mechanical cues such as flowinduced shear stress, which improves tight junction formation (Frohlich et al., 2013, 2012). The difference in dimensions caused by the $13 \%$ shrinkage is probably not the main reason for the observed difference in cell response. The authors believe that the difference has to do with the difference in material properties. PS and PES-PVP have very different mechanical properties and surface charge. The PES-PVP membranes were coated with L-DOPA, while PS membranes were not. It appears that the surface chemistry has a critical influence on the way that the topographies affect the cells. Besides, in contrast to PS surfaces, the PES-PVP membranes have more complex surface topography due to the additional (nano)topography created by the porosity.

The literature concerning the effect of substrate topography on kidney cells is quite limited. Polystyrene ridged nanostructures with depths of $100 \mathrm{~nm}$ and periodicity of $430 \mathrm{~nm}$, created by laser irradiation were able to increase the alignment of human embryonic kidney cells (HEK-293) (Rebollar et al., 2008). Compared to the current designed microstructures, the ridges in Rebolar et al. (2008) are $>2$ orders of magnitude smaller, yet the degree of alignment is very similar to that here. An interesting question for future work is whether the cell alignment is caused by the same mechanism at two different feature scales. In another study, PS ridges with a width and depth of $0.75 \mu \mathrm{m}$ were able to support HK2 cells and induce alignment of up to $24 \%$ in static flow conditions (Frohlich et al., 2012). Some current PS topographies are at least one order of magnitude larger and induce alignment of up to 54\%. As mentioned earlier alignment of kidney epithelial cells can improve tightjunction formation. Ridge topographies with very similar dimensions were also applied to polycarbonate membranes with large pores between 3 and $12 \mu \mathrm{m}$ (Frohlich et al., 2013). There, the features were very small in comparison to the membrane pores, opposite to the current case, where the membranes have large topographical features in comparison to the pores. This is possible because here the topography and porosity is formed in one step, instead of being created via subsequent embossing. This is actually an important advantage of $\mathrm{PS} \mu \mathrm{M}$ in comparison to hot embossing postmembrane fabrication, which can significantly alter the porosity, especially in the case of a membrane with relatively small pores. Despite these significant effects of membrane topography to cell morphology, preliminary transport experiments through selected microstructured PES membranes with good quality cell monolayer and cell orientation did not show improved active creatinine transport, in comparison to the nonpatterned membranes.

\section{Conclusion and outlook}

This work investigated the effect of surface topography of PS and PES-PVP membranes on the morphology, adherence and function of kidney epithelial cells. For both materials, the microtopography affects functional monolayer formation, morphology and alignment of ciPTECs and a cell monolayer can be formed without the need of ECM coatings. In contrast to the non-porous PS topographies, for most of the porous PES-PVP membranes with large features, the cell monolayer is disrupted. The PES-PVP membranes with small features and with large spacing between the features support the ciPTEC monolayer formation well.

Here, only a limited number of topographies were studied, while the TopoChip high-throughput screening platform (Unadkat et al., 2011), from which this set was derived, has more than 2100 different topographies. Following the protocol developed here, we have also performed preliminary experiments of fabricating complete porous PES TopoChips (Figure 5a). The ciPTEC culture on these porous TopoChips (using only L-DOPA coating) also showed significant effect of the topography on the cells (Figure 5b). To analyse these data further, it is planned to develop a sensitive image based assay to screen the high number of topographies developed and to identify topographies beneficial for the development of a living membrane for the BAK device. 


\section{Acknowledgements}

J.d.B., D.S. and F.H. gratefully acknowledge the financial support of the NanoNext NL initiative. J.d.B. acknowledges the financial support of the Dutch province of Limburg. C.S., D.S. and RM. .gratefully acknowledge the financial support of the Dutch Kidney Foundation and of the BioMedical Materials research program (P3.01 BioKid), co-funded by the Dutch Ministry of Economic Affairs. M.M., D.S. and R.M. gratefully acknowledge the financial support of the Marie
Curie ITN project: BIOART (grant no.316690, EU-FP7PEOPLE-ITN-2012).

\section{Disclosures}

J. de Boer and C. van Blitterswijk are shareholders of Materiomics B.V., which commercializes the TopoChip Platform.

\section{References}

Buffington DA, Westover AJ, Johnston KA et al. 2014; The bioartificial kidney. Transl Res 163(4): 342-351.

Carpenter AE, Jones TR, Lamprecht MR et al. 2006; CellProfiler: image analysis software for identifying and quantifying cell phenotypes. Genome Biol 7(10): R100.

Charest JL, García AJ, King WP. 2007; Myoblast alignment and differentiation on cell culture substrates with microscale topography and model chemistries. Biomaterials 28(13): 2202-2210.

Denker BM, Sabath E. 2011; The biology of epithelial cell tight junctions in the kidney. J Am Soc Nephrol 22(4): 622-625

Fey-Lamprecht F, Gross U, Groth TH et al. 1998; Functionality of MDCK kidney tubular cells on fla polymer membranes for biohybrid kidney. J Mater $S c$ Mater Med 9(12): 711-715.

Fey-Lamprecht F, Groth T, Albrecht W et al. 2000. Development of membranes for the cultivation of kidney epithelial cells. Biomaterials 21(2): 183-192.

Flemming RG, Murphy CJ, Abrams GA et al. 1999; Effects of synthetic micro- and nano-structured surfaces on cell behavior. Biomaterials 20(6): 573-588

Frohlich EM, Alonso JL, Borenstein JT et al. 2013; Topographically-patterned porous membranes in a microfluidic device as an in vitro model of renal reabsorptive barriers. Lab Chip 13(12): 2311-2319.

Frohlich EM, Zhang X, Charest JL. 2012; The use of controlled surface topography and flow-induced shear stress to influence renal epithelial cell function. Integ Biol (Camb) 4(1): 75-83.

Fujita Y, Kakuta T, Asano M et al. 2002; Evaluation of $\mathrm{Na}^{+}$ active transport and morphological changes fo bioartificial renal tubule cell device using Madin-Darby canine kidney cells. Tissue Eng 8(1): 13-24.

Hoffman-Kim D, Mitchel JA, Bellamkonda RV. 2010; Topography, cell response, and nerve regeneration. Annu Rev Biomed Eng 12: 203-231.

Hulsman M, Hulshof F, Unadkat H et al. 2015; Analysis of high-throughput screening reveals the effect of surface topographies on cellular morphology. Acta Biomater 15: 29-38.

Humes HD, Buffington D, Westover AJ et al. 2014; The bioartificial kidney: current status and future promise. Pediatr Nephrol 29(3): 343-351.
Ip TK, Aebischer P, Galletti PM. 1988; Cellular control of membrane permeability. Implications for a bioartificial renal tubule. ASAIO Trans 34(3): 351-355.

Jansen J, Schophuizen CM, Wilmer MJ et al. 2014; A morphological and functional comparison of proximal tubule cell lines established from human urine and kidney tissue. Exp Cell Res 323(1): 87-99.

Justesen J, Lorentzen M, Andersen LK et al. 2009; Spatial and temporal changes in the morphology of preosteoblastic cells seeded on microstructured tantalum surfaces. J Biomed Mater Res A 89(4): 885-894.

Kanai N, Fujita, Kakuta T et al. 1999; The effects of various extracellular matrices on renal cell attachment to polymer surfaces during the development of bioartificial renal tubules. Artif Organs 23(1): 114-118.

Lovmand J, Justesen J, Foss M et al. 2009; The use of combinatorial topographical libraries for the screening of enhanced osteogenic expression and mineralization Biomaterials 30(11): 2015-2022.

Lücker PB, Javaherian S, Soleas JP et al. 2014; A microgroove patterned multiwell cell culture plate for high-throughput studies of cell alignment. Biotechnol Bioeng 111(12): 2537-2548.

Luna JI, Ciriza J, Garcia-Ojeda ME et al. 2011; Multiscale biomimetic topography for the alignment of neonatal and embryonic stem cell-derived heart cells. Tissue Eng Part C Methods 17(5): 579-588.

Ni M, Teo JC, Ibrahim MS et al. 2011; Characterization of membrane materials and membrane coatings for bioreactor units of bioartificial kidneys. Biomaterials 32(6): 1465-1476

Papenburg BJ, Vogelaar L, Bolhuis-Versteeg LA et al. 2007; One-step fabrication of porous micropatterned scaffolds to control cell behavior. Biomaterials 28(11): 1998-2009.

Perrone RD. 1992; Means of clinical evaluation of renal disease progression. Kidney Int Suppl 36: S26-32.

Rebollar E, Frischauf I, Olbrich M et al. 2008; Proliferation of aligned mammalian cells on laser-nanostructured polystyrene. Biomaterials 29(12): 1796-1806.

Saito A, Sawada K, Fujimura S. 2011; Present status and future perspectives on the development of bioartificial kidneys for the treatment of acute and chronic renal failure patients. Hemodial Int 15(2): 183-192.
Sato Y, Terashima M, Kagiwada N et al. 2005; Evaluation of proliferation and functional differentiation of LLC-PK1 cells on porous polymer membranes for the development of a bioartificial renal tubule device. Tissue Eng 11(9-10): 1506-1515

Schneider CA, Rasband WS, Eliceiri KW. 2012; NIH Image to ImageJ: 25 years of image analysis. Nat Methods 9(7): 671-675.

Schophuizen CM, De Napoli IE, Jansen J et al. 2015 Development of a living membrane comprising a functional human renal proximal tubule cell monolayer on polyethersulfone polymeric membrane. Acta Biomater 14: $22-32$.

Schophuizen CM, Wilmer MJ, Jansen J et al. 2013; Cationic uremic toxins affect human renal proximal tubule cell functioning through interaction with the organic cation transporter. Pflugers Arch 465(12): 1701-1714.

Unadkat HV, Hulsman M, Cornelissen K et al. 2011; An algorithm-based topographical biomaterials library to instruct cell fate. Proc Natl Acad Sci U S A 108(40): $16565-16570$

Van der Aa MA, Helmerhorst TJ, Siesling S et al. 2010 Vaginal and (uncommon) cervical cancers in the Netherlands, 1989-2003. Int J Gynecol Cancer 20(4): 638-645.

Van Itallie CM, Fanning AS, Bridges A et al. 2009; ZO-1 stabilizes the tight junction solute barrier through coupling to the perijunctional cytoskeleton. Mol Biol Cell 20(17): 3930-3940.

Vogelaar L, Lammertink RG, Barsema JN et al. 2005; Phase separation micromolding: a new generic approach for microstructuring various materials. Small 1(6): 645-655.

Wilmer MJ, Saleem MA, Masereeuw R et al. 2010. Nove conditionally immortalized human proximal tubule cel line expressing functional influx and efflux transporters. Cell Tissue Res 339(2): 449-457.

Zhang H, Tasnim F, Ying JY et al. 2009; The impact of extracellular matrix coatings on the performance of human renal cells applied in bioartificial kidneys. Biomaterials 30(15): 2899-2911.

Zhu LP, Yu JZ, Xu YY et al. 2009; Surface modification of PVDF porous membranes via poly(DOPA) coating and heparin immobilization. Colloids Surf B Biointerfaces 69(1): 152-155

\section{Supporting information}

Additional Supporting Information may be found online in the supporting information tab for this article.

Supplementary Figure 1. Transport of creatinine and inulin by ciPTEC cultured on porous PES membranes with various topographies. The graphs show mean inulin and creatinine transport from two experiments 